\title{
dosalgarves, www.dosalgarves.com
}

\section{Story Map Caminhos d'o Conspirador: Um percurso literário na vila de Marvão com Branquinho da Fonseca}

\section{Story Map Caminhos d'O Conspirador: A literary itinerary in Marvão with Branquinho da Fonseca}

\author{
Aquilino Machado \\ Centro de Estudos Geográficos, IGOT, Universidade de Lisboa, Portugal \\ aquilino.machado@campus.ul.pt \\ Conceição Machado \\ Escola Superior de Hotelaria e Turismo do Estoril (ESHTE), Portugal \\ conceicao.machado@eshte.pt
}

\section{Fernando João Moreira}

Escola Superior de Hotelaria e Turismo do Estoril (ESHTE), Centro de Estudos Geográficos, IGOT, Universidade de Lisboa, Portugal

fernando.moreira@eshte.pt

\section{João Reis}

Escola Superior de Hotelaria e Turismo do Estoril (ESHTE), Centro de Investigação, Desenvolvimento e Inovação em Turismo (CiTUR), Portugal

joao.reis@eshte.pt

\section{Maria José Aurindo}

Escola Superior de Hotelaria e Turismo do Estoril (ESHTE), Portugal

maria.aurindo@eshte.pt

\section{Maria Mota Almeida}

Escola Superior de Hotelaria e Turismo do Estoril (ESHTE), Instituto de História Contemporânea da Universidade Nova de Lisboa, Portugal

maria.almeida@eshte.pt

\section{Rita Faria}

Escola Superior de Hotelaria e Turismo do Estoril (ESHTE), Portugal

rita.faria@eshte.pt

\begin{abstract}
Resumo
Os autores pretendem apresentar uma nova forma de divulgação da investigação em turismo literário, num formato mais atrativo, recorrendo às novas tecnologias e bem assim, aferir as suas potencialidades. A ferramenta tecnológica utilizada foi o story map que permite combinar mapas na Web com aplicações e templates que incorporam funções interativas e mapas dinâmicos. Um dos recursos utilizados na produção do story map foi a base de dados do Museu Virtual de Turismo (MUVITUR) em cujo site o produto final será disponibilizado. Os conteúdos e itinerários turísticos literários organizados por especialistas permitem envolver os viajantes online nas geografias imaginárias, para as quais os escritores nos remetem. Experiências virtuais mais envolventes possibilitam a cada utilizador a descoberta dos melhores percursos por territórios literários. O objeto do presente trabalho foi o conto "O Conspirador", de Branquinho da Fonseca (1905-1974) tendo o percurso na vila de Marvão sido enriquecido com desenhos e fotografias da sua autoria.
\end{abstract}

Palavras-chave: Branquinho da Fonseca; turismo literário; Marvão; MUVITUR; story map. 


\begin{abstract}
The authors intend to present a more attractive format to disseminate research in literary tourism, making use of new technologies. The story map is the technological tool used, and it allows the combination of online maps with apps and templates that incorporate interactive functions and dynamic maps. One of the resources the authors use in the production of the story map is the database of the Virtual Tourism Museum (MUVITUR) on whose website the final product will be made available. The literary content and tourist itineraries organized by specialists allow online travellers to be involved in imaginary geographies created by writers. More engaging virtual experiences enable users to discover the best routes through literary territories. The object of the present study was the short story "O Conspirador", by Branquinho da Fonseca (1905-1974) and the itinerary in the village of Marvão was enhanced by drawings and photographs authored by the writer.
\end{abstract}

Keywords: Branquinho da Fonseca; literary tourism; Marvão; MUVITUR; story map.

\title{
1. Introdução
}

O presente artigo é constituído por três partes. Num primeiro momento, faz-se a identificação do tema e a apresentação dos objetivos. Segue-se a revisão da literatura, a contextualização e as opções metodológicas conduzidas pela equipa. Por último discutem-se os resultados obtidos e apresentam-se as conclusões.

Este trabalho surge no âmbito da pesquisa para preparação de uma candidatura a um projeto de investigação sob o tema do turismo literário em que identificámos a oportunidade de explorar uma ferramenta tecnológica de storytelling, o Story map capaz de potenciar o reconhecimento de algumas das dimensões do território literário, possibilitando a contextualização georreferenciada da leitura de extratos de obras literárias.

De acordo com (Quinteiro \& Baleiro, 2017: 71), "no contexto do turismo literário, os textos literários tomam a forma de guias turísticos, criando e assinalando lugares a visitar e a conhecer, desenhando mapas a partir dos quais o turista/leitor pode orientar-se e realizar diversos tipos de percursos". No caso que ora apresentamos, partimos de uma publicação onde o itinerário literário, de cariz local, já estava delineado e publicado online por uma entidade pública. Um dos objetivos desta proposta é igualmente poder contribuir para a valorização de um espaço e do seu património num território de baixa densidade como é o caso de Marvão.

Conquanto se apresente como um estudo de caso em que os autores se propõem utilizar uma ferramenta tecnológica na divulgação da literatura portuguesa e na exploração de territórios literários, também será importante salientar que a metodologia e resultados aqui apresentados poderão servir como estudo exploratório para a sua replicação em contextos semelhantes.

A função do MUVITUR - Museu Virtual do Turismo é a de reunir o património associado às manifestações do lazer e da atividade turística e hoteleira. Recolhe, organiza, expõe e disponibiliza objetos digitais relacionados com estas temáticas, recorrendo a uma plataforma online, agregadora de conteúdos provenientes de diversos fornecedores (arquivos, bibliotecas, museus e outros). Pretende reconstituir, investigar e preservar memórias, através de exposições, eventos e projetos de investigação que permitam consolidar conhecimento e perspetivar a história da indústria do turismo.

Os museus virtuais podem apresentar-se como contadores de histórias que facilitam a disseminação da literatura, oferecendo olhares e narrativas para novos e enriquecedores encontros com a história. Os atores responsáveis pelo património cultural digital, que tanto 
têm investido na sua digitalização e disponibilização massiva, podem abraçar as novas tecnologias de informação e comunicação de forma a oferecer serviços culturais digitais inovadores baseados na edição de conteúdos, nomeadamente através do digital storytelling enquanto: "creative way to favour access to digital cultural heritage throughout Europe and beyond to a wide public, contributing to transnational circulation of European heritage and knowledge dissemination" (Brouillard, Loucopoulos \& Dierickx, 2015: 8).

Por seu lado, são abundantes as relações já identificadas entre narrativas e cartografia que citam não apenas o crescente reconhecimento do significado da visualização da informação espacial, mas também a importância da espacialidade nas artes e nas ciências sociais (Caquard, 2013: 135).

Estes processos procuram sobretudo comunicar criativamente e envolver emotivamente as pessoas nas mensagens veiculadas através das narrativas, contando histórias, reforçando identidades territoriais ou ainda cartografando emoções, estimulando, reinterpretando, o que Aitken e Craine (2006) referem como geovisualizações afetivas.

\section{Revisão de literatura}

\subsection{Paisagens literárias, turismo e desenvolvimento local}

A narrativa de alguns escritores reporta-se, por vezes, a determinados territórios sentimentais que servem de base à criação simbólica de cenários literários. Essa identificação está subjacente em incontáveis obras literárias, sobretudo nas de natureza ficcional, despertando sentimentos de identidade e de pertença junto de quem compare os cenários descritos com os territórios reais. Nestes contextos, parecem ocasionar uma imensa trama cartográfica absorvida na materialidade dos sítios, onde continua presente a memória criativa do escritor (Machado, 2020; Machado \& Moreira, 2018).

As experiências conhecidas mostram que entre os observadores informados se estabelece uma forte conexão entre a descrição literária dos sítios e a respetiva realidade concreta, e daí a sua predisposição para acolherem favoravelmente todas as medidas que, nesse contexto, visem promover o respetivo desenvolvimento sustentável e perdurável. Por via dessa simultaneidade, as paisagens da escrita assumem-se como um dos traços mais perduráveis no desenho das nossas vidas, ao fidelizarem um território com a sua memória e semeando os contornos de uma ideia plena e sustentável para a sua salvaguarda, sobretudo quando o registo de uma sociedade muda de uma forma tão profunda e acelerada, e a marca de uma paisagem física e humana se torna, invariavelmente, esboço de relíquias e de destroços (Domingues, 2012).

Justamente por isso é que se sublinha a progressiva importância que as paisagens literárias têm vindo a adquirir na criação de territórios sustentáveis e na valorização das suas potencialidades endógenas (Moreira, 2008; Queiroz, 2009; Machado, 2020; Machado e Moreira, 2018). Ora, ao ser projetada como um conceito de alcance contemporâneo, a paisagem literária assume uma correspondência cultural e uma perspetiva vincadamente ideológica. Na verdade, as relações ecológicas e os equilíbrios paisagísticos inerentes a determinadas regiões, e a relevância dos cenários literários a que estão ligadas verbalizam a estratégia atual da União Europeia (UE), que se encontra harmonizada através da Convenção Europeia da Paisagem, ao promover o conhecimento alargado do papel que a paisagem desempenha em diversas funções de interesse público, "nos campos cultural, ecológico, ambiental e social, e constitui um recurso favorável à atividade económica, cuja proteção, 
gestão e ordenamento adequados podem contribuir para a criação de emprego" (preâmbulo da Convenção Europeia da Paisagem). Por consequência, uma das formas de rentabilizar a salvaguarda das paisagens, sem perda das suas múltiplas dimensões, assentará na dinamização de alternativas de desenvolvimento turístico que, além de incorporarem o conceito de desenvolvimento ambiental, assimilem "outras preocupações que, no seu conjunto, vão alargar a ideia de sustentabilidade a mais dois outros vetores: a sustentabilidade social e económica" (Moreira, 2008: 156).

É nesta margem que também nos interessa situar algumas modalidades de turismo cultural, nomeadamente as que assentam na valorização turística das paisagens literárias (Machado, 2020; Quinteiro \& Baleiro, 2017). Certos conspectos incidem sobre o modo como as paisagens geográficas, e as suas correspondentes paisagens literárias, geram fenómenos de atratividade sobre os turistas e como se compaginam os fatores que lhe estão subjacentes (Bouvet, 2019; Quinteiro \& Baleiro, 2017). Herbert (1996) realça a importância que as obras literárias e artísticas exercem na consolidação de uma estratégia de turismo cultural, em determinados territórios franceses. A procura dos lugares mágicos, dos sítios imaginários, e a sua associação com personagens fictícias é então realçada por este autor quando fala nas paisagens literárias de escritores ingleses e irlandeses:

In these places, a visitor can still today walk out of a house and into landscapes which have a barely changed since the writer drew breath from them and breathed literature into them ... We walk in our writers' footsteps and see through their eyes when we enter these spaces. (Marsh, 1993 apud Herbert, 1996: 77)

Em Portugal contam-se já algumas estratégias devidamente integradas, que constituem um produto de desenvolvimento endógeno alicerçado na exploração de paisagens literárias. Algumas delas conciliam algumas vocações específicas, como nos referem Quinteiro e Baleiro (2017: 40), ao citarem Mansfield, quando fazem das casas dos escritores "lugares abertos a visitantes, e ainda" outras "nos quais são as autoridades locais que desempenham uma função determinante na criação e divulgação dos lugares e espaços literários”. Foi esta a fórmula que se procurou desenvolver com a criação de uma rede de Casas-Museu de escritores, as quais juntando um conjunto relevante de promotores turísticos se conformam como agentes de harmonização entre o conhecimento das relações ecológicas, a sensibilidade estética e a perceção dos espaços (Queiroz, 2009). Correlativamente ao que é desenvolvido para a generalidade dos países europeus, as paisagens literárias proclamam-se através de um tratamento turístico que, conseguindo aproveitar um conjunto de ações culturalmente polivalentes, alcançam a partir delas novas e inovadoras estratégias de preservação patrimonial (Machado, 2020). Nada que atinja, no entanto, a dimensão contida no território francês, onde a incidência cartográfica supera a centena de casas, devidamente suportadas por novas tecnologias de informação, que valorizam um princípio da inter-conectividade territorial, nomeadamente através do portal da "Association Terres d'Écrivains", ou da parceria recenseadora "Carte de France des Maison d'Écrivains des Patrimoines Littéraires" (Sardo, 2009).

Algumas destas estratégias associam experiências turísticas singulares demonstrando que, cada vez mais, os destinos são escolhidos para circunstanciar um maior conhecimento dos lugares, e onde os turistas assumem um papel de atores ativos no enredo procurado (Machado, 2012). Aquilo a que Quinteiro e Baleiro (2017: 40) aludem como uma dimensão a 
considerar que passa, não pela adequação da oferta à procura, mas, como refere Martino Alba, "por criar uma oferta que gera ela própria uma procura anteriormente inexistente", no qual o visitante se sente integrado como num espaço em que a fronteiras entre o real e o ficcionado se diluem e em que ele se integra na narrativa como se estivesse a vivê-la.

Estes exemplos assumem-se, em grande parte, no estabelecimento das modalidades de turismo a desenvolver em contextos de baixa densidade, mediante a valorização das suas potencialidades endógenas segundo estratégias que visem contrariar a desruralização dos territórios interiores. Ou, conforme alude Domingues (2012: 69), a acentuada "perda da importância da atividade agrícola (...) e das culturas e modos de vida rurais tradicionais das sociedades camponesas", a qual, em boa medida, se deve a um conjunto de fatores, nomeadamente o "recuo demográfico o despovoamento e o abandono do solo agrícola".

Um compromisso que se ampara em conceitos de sustentabilidade e responsabilidade na reflexão do turismo e que concorrem para que as suas finalidades devam lograr "para além das condições de vida das populações, e num nível semelhante, a conservação do ambiente, a valorização das culturas locais e a promoção de um espírito de tolerância e diálogo intercultural" (Henriques, 2010: 223).

É sobre os alicerces de uma destas paisagens e a sua importância como lugar de criação da escrita que em seguida nos dedicaremos.

\subsection{Conto 'O Conspirador’}

Impressionou-me agradavelmente encontrar Marvão a percorrer o país dentro d'um livro de belos contos. [...] E o livro, nesta quadra do ano, aqui em Marvão, tem ainda outra circunstância a prender a nossa atenção: as procissões de noite e de dia; ainda há pouco foi a última, tal como lá vem magistralmente pintada. (Palha, 1938, apud Almeida \& Oliveira, 2018: 70)

António José Branquinho da Fonseca estava já a habitar na Nazaré quando recebe esta carta, vinda de Marvão, a propósito da publicação do conto 'O Conspirador', inserido na coletânea Caminhos Magnéticos (1938). O escritor, presencista, esteve colocado em Marvão, entre 19351936, como Conservador do Registo Civil, inspirando-se nesta região para a sua escrita. Quase oitenta anos depois também nós, concordando com o autor da missiva, nos deixámos deslumbrar pela paisagem natural e humana aí retratada, pelo belíssimo "mapa de palavras" (Quinteiro \& Baleiro, 2017: 72), decidindo divulgar o autor, a obra e a localidade mediante a criação de itinerários literários. Neste sentido, propusemos à Câmara Municipal de Marvão a realização de um projecto que relacionasse uma oferta turística diversificada, visando contribuir para o desenvolvimento do destino turístico de Marvão, com a sustentabilidade local e valorização das suas potencialidades endógenas. Assim, em 2014, a autarquia iniciou, entusiasticamente, o apoio ao projeto de turismo literário, Os Caminhos d'O Conspirador, materializado no e-book que serviu de base ao trabalho que agora se apresenta (Almeida \& Oliveira, 2018).

O conspirador revolucionário e protagonista do conto, Paulo Mascarenhas de Albuquerque, jornalista, para quem a capital significa detenção e a província the permite a clarividência para traçar o futuro, viaja de noite e vai refugiar-se, em Marvão, na casa dos avós do seu amigo Eduardo. Ao refúgio corresponde a "paz da vilória morta, onde não chegavam bulícios do mundo, onde não havia jornais nem notícias de nada” (Almeida \& Oliveira, 2018: 22) mas, igualmente, a solidão que o longo isolamento pode propiciar. 
Paulo só conhecia as solidões modernas: o quarto de aluguer e a multidão das cidades no meio da qual se anda tão só que nos sentimos longe de nós próprios. Mas essa não é a verdadeira solidão. A verdadeira é no alto de uma montanha. Porque é indispensável a continuidade que aumenta a tensão até ao limite da resistência. É aí que começa a claridade. (Almeida \& Oliveira, 2018: 23)

Esta solidão levou-o a uma reflexão profunda sobre os passos a seguir, começando "a olhar a vida e as ideias sob uma luz nova" (Almeida \& Oliveira, 2018: 23). A presença e, mais tarde, a companhia de Maria Ricarda, "alta e elegante, bonita, de grandes olhos luminosos" (Almeida \& Oliveira, 2018:20), ajuda a quebrar o isolamento, visto que "o excesso de solidão escangalhame os nervos". Paulo, depois de ter permanecido em Marvão, é obrigado a fugir para Espanha, por causa da perseguição da polícia, com ordens do governo militar para prender os responsáveis pela "miserável rebelião dum bando de criminosos da mais baixa espécie" (Almeida \& Oliveira, 2018: 13). Como se encontra numa terra de viagens de contrabando, motivadas por necessidades económicas, aproveita as ancestrais estratégias de fuga para 'dar o salto', com a ajuda do Falcoeiro, homem experiente que "conhecia a região como os cantos da própria casinhota onde vivia. Desde os 7 anos que andava neste vaivém de passa fronteira, carregado de café e de galinhas, na ida para Espanha, ajoujado de alparcatas e sedas, na volta" (Almeida \& Oliveira, 2018: 32), protegido pela Senhora da Estrela. É este homem que, ultrapassando todos os obstáculos, o conduz, pela calada da noite, são e salvo, a Valencia de Alcántara e o leva, também clandestinamente, para os encontros com a sua "doce apaixonada", em Marvão:

\begin{abstract}
E assim chegaram à outra margem que era Portugal. Vestiram-se e a pele molhada depressa enxugaria com o puxar pela ladeira acima. Dali para diante, o Falcoeiro foi andando bem à frente, como cão de venta fina. E lá iam. Não se via estrela no Céu nem luz na Terra e Paulo meditava nos perigos destas incursões. Mas a força que o levava não era das que dão grandes prudências a alguém. Sobre todas as coisas e contra todas, punha agora o seu amor invencível. De cinco sentidos alerta, já distinguia bem a sacudida fuga dum coelho ou o silencioso sumir da raposeta. (Almeida \& Oliveira, 2018: 33)
\end{abstract}

O vaivém constante entre os dois lados da fronteira não vai durar muito, visto que a incerteza quanto ao futuro obriga Paulo a uma aventura incessante e a permanentes viagens que o levam a Marselha, Timor e Nagasaki. Viagens estas que, se por um lado, são libertadoras, por outro fazem-no sentir agrilhoado: "Livre! E a fugir! Que paradoxo." (Almeida \& Oliveira, 2018: 36).

O conto, dedicado ao amigo presencista Edmundo de Bettencourt, termina com um sinal de esperança e de resistência: “Caminhar sempre!" (Almeida \& Oliveira, 2018: 36). Caminhemos nós, também, acompanhando o escritor e a experiência por ele vivida. $O$ ambiente que nos transmite permite recuperar e (re)construir uma memória do espaço e tempo, possibilitando uma reedificação do passado, dos hábitos, história(s), testemunhos e quotidianos de um lugar. Permite caracterizar a identidade cultural de Marvão e das suas gentes, registando o património construído, ambiental e imaterial. Através dele, do conjunto de fotografias e dos desenhos realizados pelo autor, é possível viajar num tempo que ainda hoje está muito presente naquela localidade do Alentejo. Permite caracterizar a identidade de Marvão, "um monte de casas sobre um penhasco de pedra negra" (Almeida \& Oliveira, 2018: 13) e das suas gentes, registando o património construído, ambiental e imaterial. O burgo é composto por: "um labirinto de escadinhas toscas e vielas íngremes. As habitações, muito 
caiadas, com buracos que são janelas e com portas medievais em ogiva, roídas dos séculos, estão umas a cavalo nas outras, no alto do monte, a olhar para Espanha." (Almeida \& Oliveira, 2018: 17).

O que o escritor enaltece, com grande deslumbramento, "numa descrição que tem muito de cinematográfico" (Martinho, 2007: 14) é a paisagem sempre pontuada por animais: "Lá para baixo contempla-se o mundo em mapa de relevo a belas cores: montes, rios, planícies, aldeias brancas, estradas, florestas. E as águias, vêem-se pelas costas, pairando em volta do despenhadeiro." (Almeida \& Oliveira, 2018: 47).

O património, "DNA do território e da comunidade" (Varine, 2012: 45), eternizado por Branquinho da Fonseca, com a riqueza descritiva das paisagens, da fauna e flora, do património construído e dos hábitos da comunidade, a forma como, em suma, comunica (com) o território, permite elaborar dois itinerários que nos possibilitam viajar na urbe e na zona rural: o percurso literário intramuralhas, que serviu de base ao story map apresentado, e o percurso pedestre do Contrabando entre Marvão e Valencia de Alcántara (Cáceres) via La Foñtanera.

A valorização territorial, através da literatura, implicou que o Conto fosse o pretexto para o levantamento de outras literaturas e culturas de Marvão e se estabelecessem conexões, algumas das quais bastante frutuosas, com outros territórios apropriados por Branquinho da Fonseca: Mortágua, Coimbra, Cabeceiras de Basto, Nazaré, Lisboa, Cascais e Açores, que poderíamos designar por territórios branquinianos.

\subsection{Branquinho da Fonseca}

Nascido há 115 anos (1905) nas Laceiras (Mortágua), filho do polémico escritor Tomás da Fonseca, António José Branquinho da Fonseca, licenciou-se em Direito na Universidade de Coimbra.

Em 1924, nesta cidade, lança a revista Tríptico, mas é em 1927 que funda, em conjunto com José Régio e João Gaspar Simões, a revista Presença, folha de arte e crítica, que se "converteria num dos mais influentes e duradouros órgãos literários de Portugal" (Neves, 2011: 134). Esta revista foi responsável pela divulgação da obra de autores modernistas, muito pouco conhecidos na altura: Mário de Sá-Carneiro, Fernando Pessoa, Almada Negreiros, Mário Saa, Camilo Pessanha, António Botto, Raul Leal, António Ferro, etc. Além da participação nas revistas, Branquinho da Fonseca escreveu novelas, contos, um romance e poesia utilizando, por vezes, o nome de António Madeira. A sua escrita revela uma visão cheia de simbolismo e realismo, hábil em misturar o fantástico e o palpável, destacando-se pela intensidade psicológica das suas personagens e pelas descrições, quase cinematográficas, que habilmente tece dos locais narrados, das suas gentes, costumes e tradições, misturando o descritivo com uma boa dose de ironia. No ano da sua formatura, em 1930, abandona a Presença (n. ${ }^{\circ} 26$ AbrilMaio) e funda a revista Sinal, juntamente com o também 'dissidente' Miguel Torga, da qual só sai um número. Começa a trabalhar, em Coimbra, como ajudante de Conservador de Registo Civil. Pouco tempo depois foi colocado como Conservador do Registo Civil em Marvão, e depois na Nazaré - nesta localidade acumula o Registo Civil com o Predial, fixando residência em Cascais no final da década de 30. Na Nazaré, em 1939, concretiza mais um sonho: criar a Biblioteca. É o sócio n. ${ }^{\circ} 1$.

Enquanto Conservador do Museu-Biblioteca Condes de Castro Guimarães - Cascais - inicia, em 1953, a experiência das bibliotecas móveis. Infatigável divulgador dos livros e da leitura, 
desenvolveu, a partir de 1958, por convite de Azeredo Perdigão, o Serviço de Bibliotecas Itinerantes e Fixas da Fundação Calouste Gulbenkian, tendo sido o seu primeiro diretor.

Além da escrita e das 'suas' Bibliotecas Itinerantes, Branquinho da Fonseca explorou campos tão diversos como a tradução, a organização de antologias, a marcenaria, o desenho, a gravação em linóleo e madeira, o grafismo, do qual destacamos o logótipo da revista presença, e a fotografia, onde ensaiou o mistério, o horror e o fantástico. Legou-nos um vasto conjunto de fotografias, apresentando-nos trechos dos locais onde habitou e que permitem, em certos casos, ilustrar as suas narrativas.

A geografia literária e sentimental de Branquinho da Fonseca cruza-se, em parte, com a sua geografia biográfica. Coimbra, Nazaré e Marvão servem como fonte de inspiração para algumas das suas obras literárias, permitindo que a escrita acompanhe o espaço e o espaço influencie a escrita. Outras localidades, onde não habitou, são igualmente retratadas nas suas obras, como é o caso de Cabeceiras de Basto, Lisboa e Vale do Tejo e as ilhas açorianas, conforme se pode observar no mapa infra.

Figura 1. A geografia literária de Branquinho da Fonseca

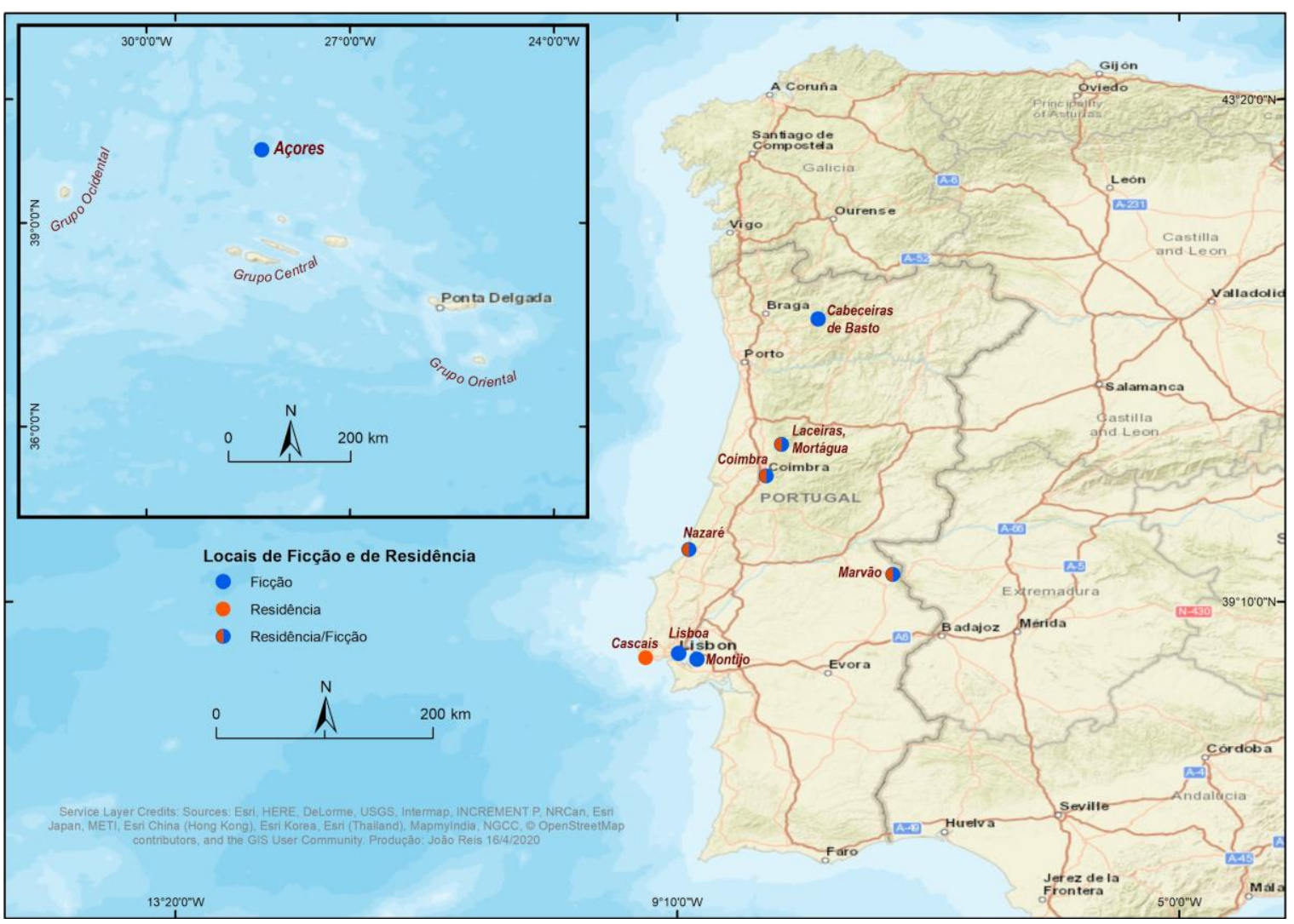

\section{Metodologia}

Numa primeira fase, verificou-se a existência no catálogo do MUVITUR de objetos digitais relevantes para a ilustração do Story map e foram feitas pesquisas de outros conteúdos passíveis de serem migrados por parte de fornecedores parceiros do MUVITUR, sendo que o 
e-book Os Caminhos d'O Conspirador foi o documento base que contém os itinerários turísticos propostos pelos seus autores.

O Story map é um aplicativo que permite informar e promover na web conteúdos, geográficos, turísticos, históricos, literários, entre outros, através da combinação de funções interativas com mapas personalizados e dinâmicos que fazem parte da narrativa digital, ilustrando relações espaciais, de forma apelativa e credível. Este aplicativo está integrado no ArcGIS Online, que é a infraestrutura geocolaborativa de SIG (Sistemas de Informação Geográfica) e representação cartográfica na cloud da Esri Portugal: Sistemas de informação geográfica, isto é, um software-as-a-service (SaaS) que não requer conhecimentos de programação, permitindo facilmente a publicação e a partilha da informação.

A partir do menu "conteúdo", que possibilita a criação de uma aplicação web configurável, foi utilizado o template Cascade disponibilizado pelo nosso parceiro Esri Portugal: Sistemas de informação geográfica (Figuras 2 e 3).

Figura 2. Screenshots do ArcGIS Online para selecionar a aplicação web configurável

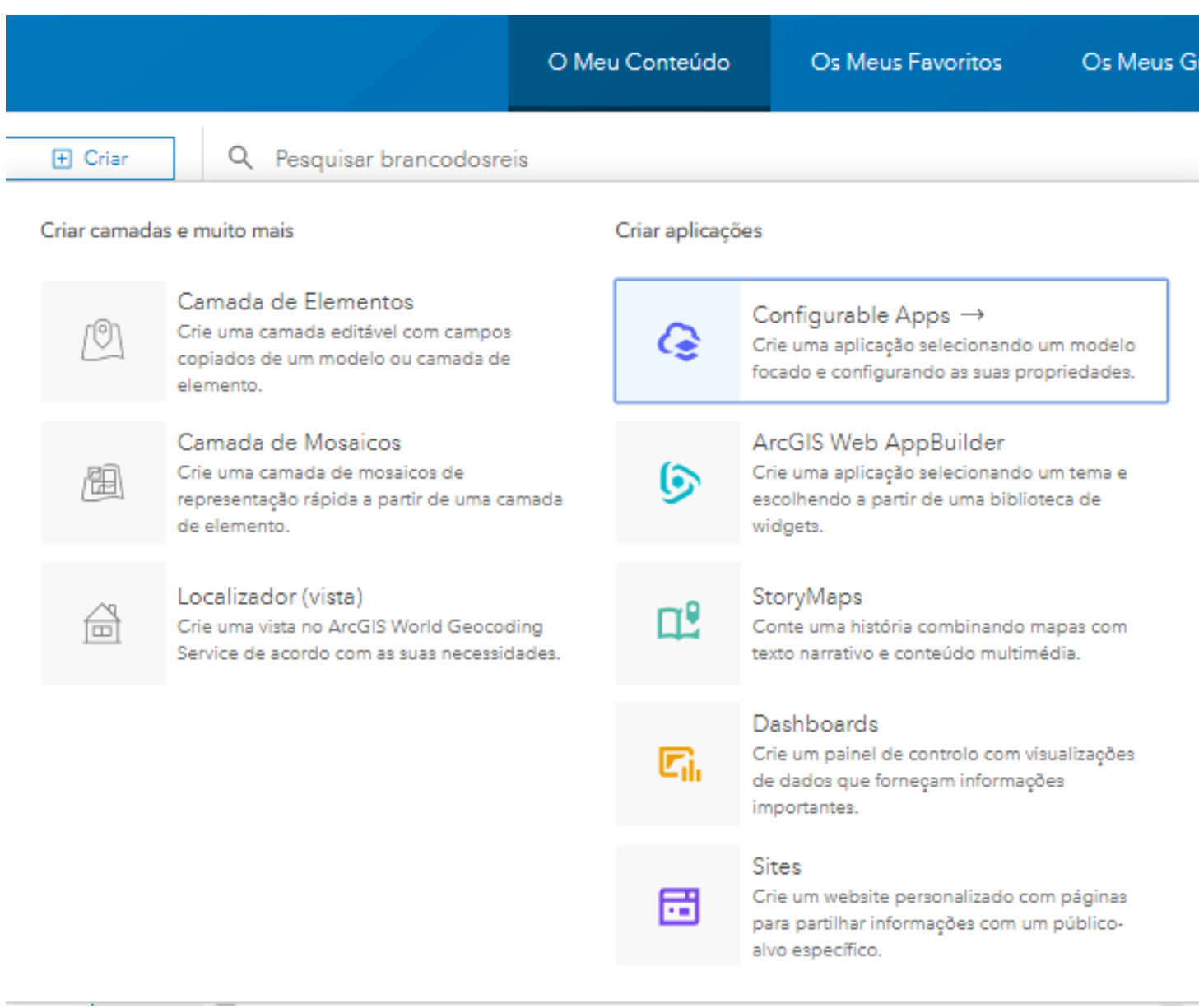

Fonte: Esri Portugal: Sistemas e informação geográfica (2020). 
Figura 3. Screenshots do ArcGIS Online para selecionar o Story map - template Cascade

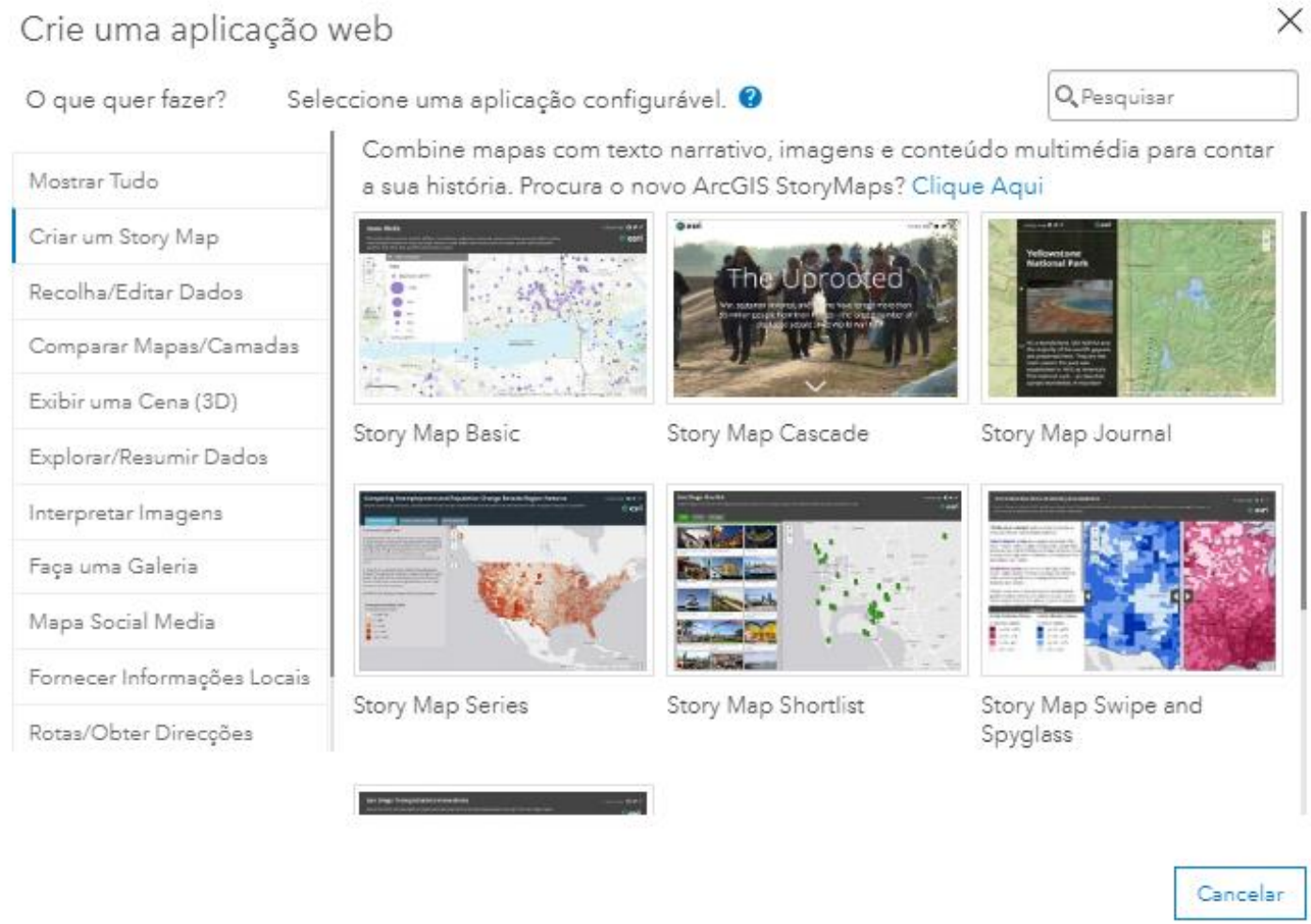

Fonte: Esri Portugal: Sistemas de informação geográfica (2020).

Após a organização dos guiões narrativo e técnico, foram trabalhados o design gráfico e os conteúdos multimédia, com recurso aos softwares Adobe Premiere Pro (com publicação na plataforma YouTube), Adobe Photoshop e Adobe Illustrator.

As vectorizações dos locais de interesse e do percurso na vila de Marvão foram realizadas no software de Sistemas de Informação Geográfica (SIG) - ArcGIS (ArcMap), utilizando os diversos mapas de base disponíveis, e incorporadas no Web Map (ArcGIS Online), ficando automaticamente disponíveis no Story map (Figura 4). 
Figura 4. Screenshot do ArcGIS Online (webmap)

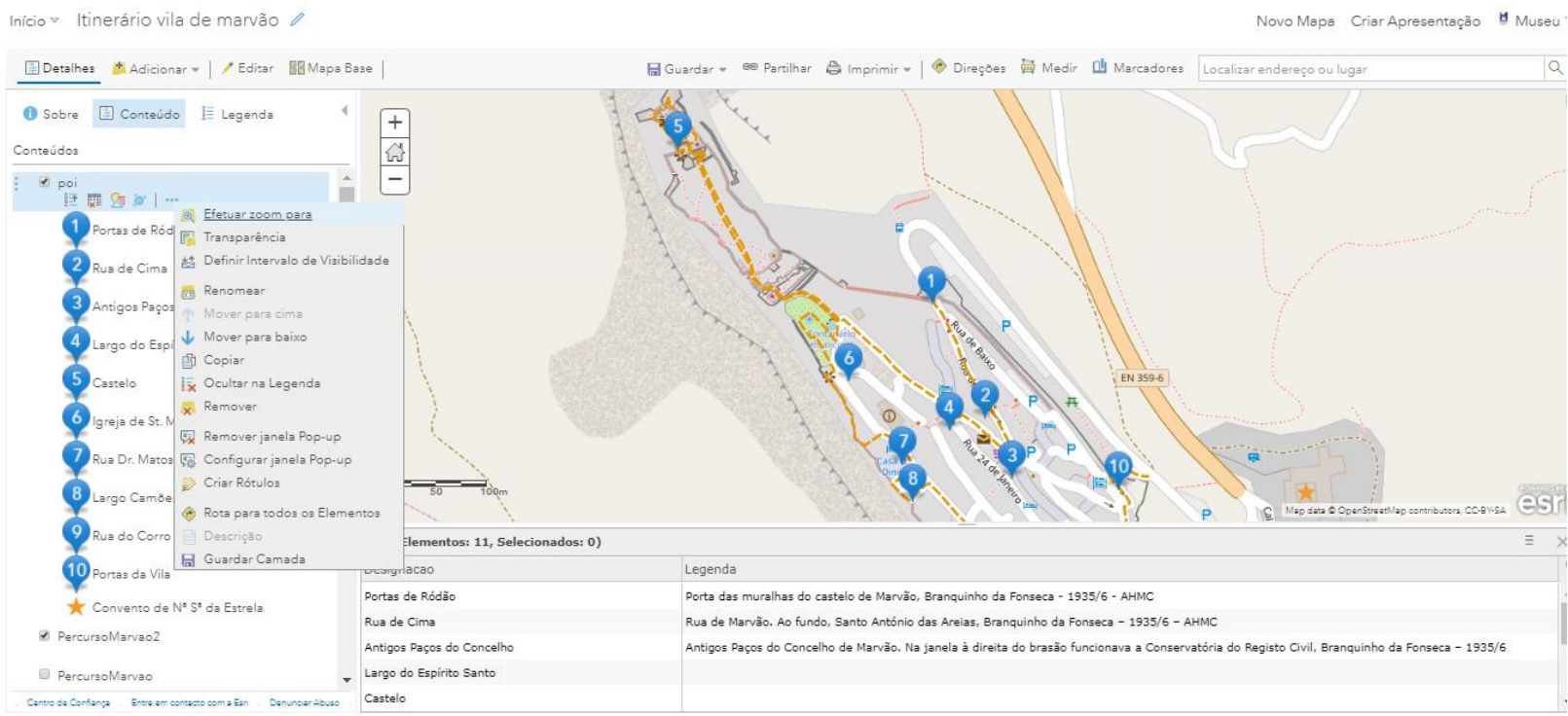

Após a integração dos dados no ArcGIS Online, procedeu-se à personalização dos locais de interesse e do percurso. Por último, foram integrados os pop-ups dos locais de interesse com ligação ao catálogo do MUVITUR, permitindo produzir o output final disponibilizado no âmbito das experiências oferecidas pelo MUVITUR (Figura 5).

Figura 5. Screenshot do ArcGIS Online (pop-up das Portas de Ródão)

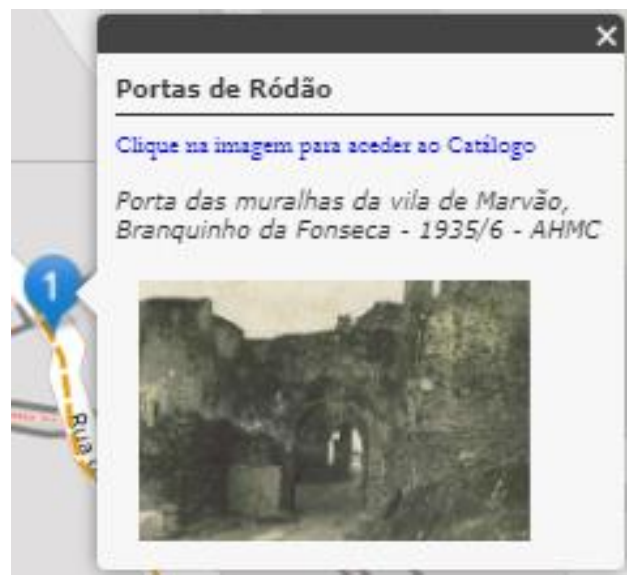

\section{Resultados e discussão}

A articulação dos sistemas digitais utilizados permitiu a produção de vários conteúdos digitais que foram integrados no Story map Os Caminhos d'O Conspirador: itinerário da vila de Marvão. Na Figura 6, apresenta-se o vídeo de introdução ao Story map, no qual é possível observar a paisagem extraordinária de Marvão, território sobre o qual escreveram Branquinho da Fonseca e os autores do e-book que se percorre neste artigo. 


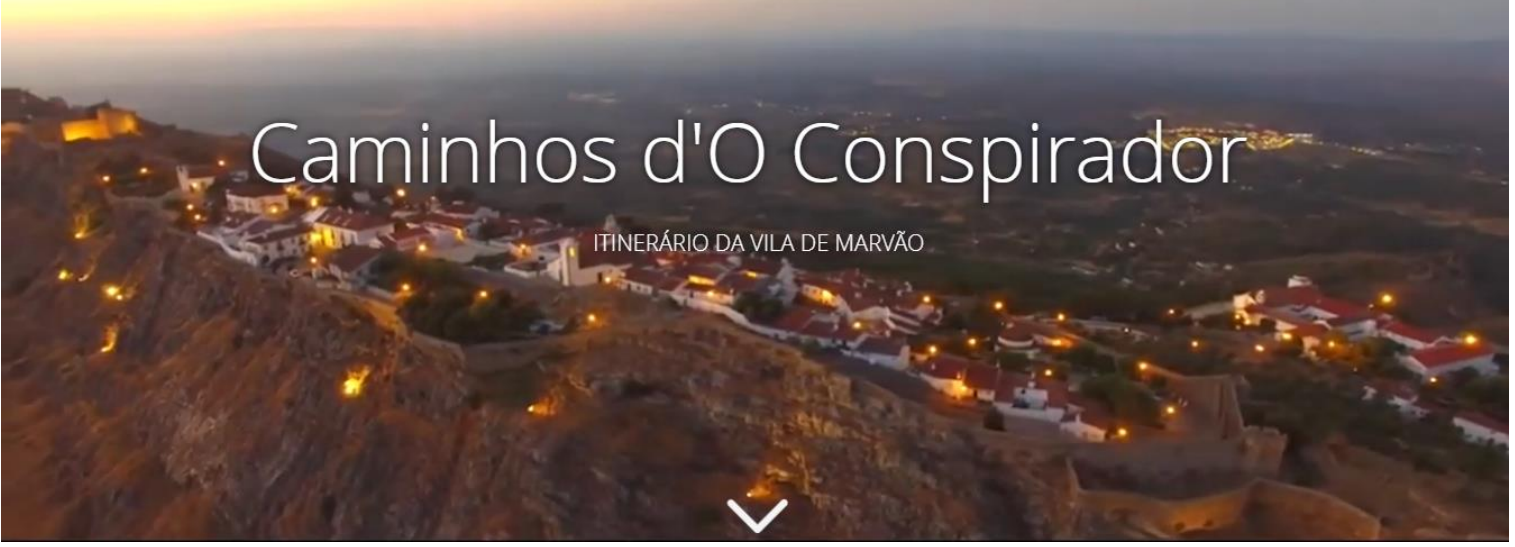

No início deste Story map apresenta-se o autor António José Branquinho da Fonseca (19051974), incluindo uma adaptação do retrato do mesmo por José Régio (1928) (Figura 7).

Figura 7. Screenshot do Story map com a apresentação do autor

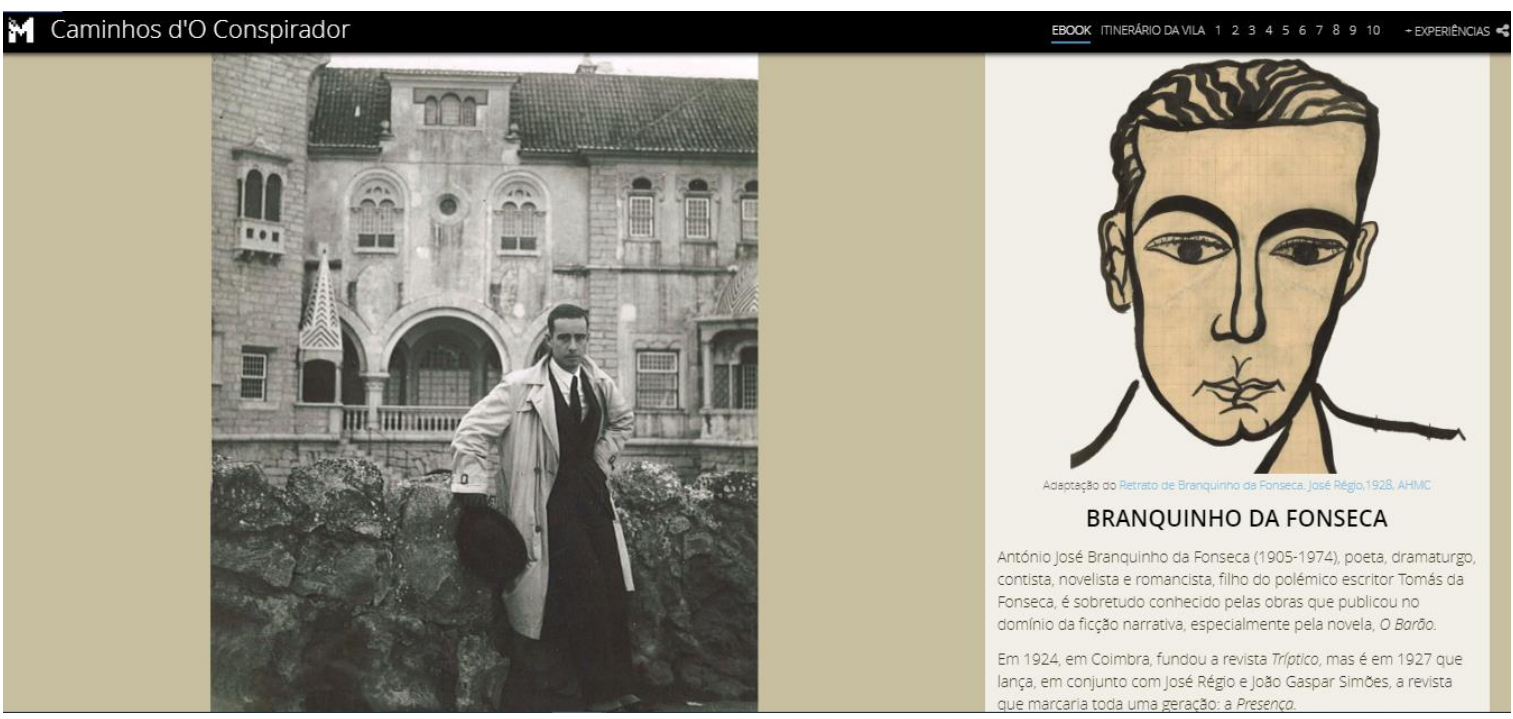

Na Figura 8, o Story map apresenta um mapa com a indicação do percurso literário e dos locais com interesse para visitar, com base na escrita de Branquinho da Fonseca, bem como a ficha técnica com as seguintes informações: percurso pedestre, distância de cerca de 2 quilómetros, duração aproximada de 3 horas, dificuldade média e acessibilidade não contemplada. 


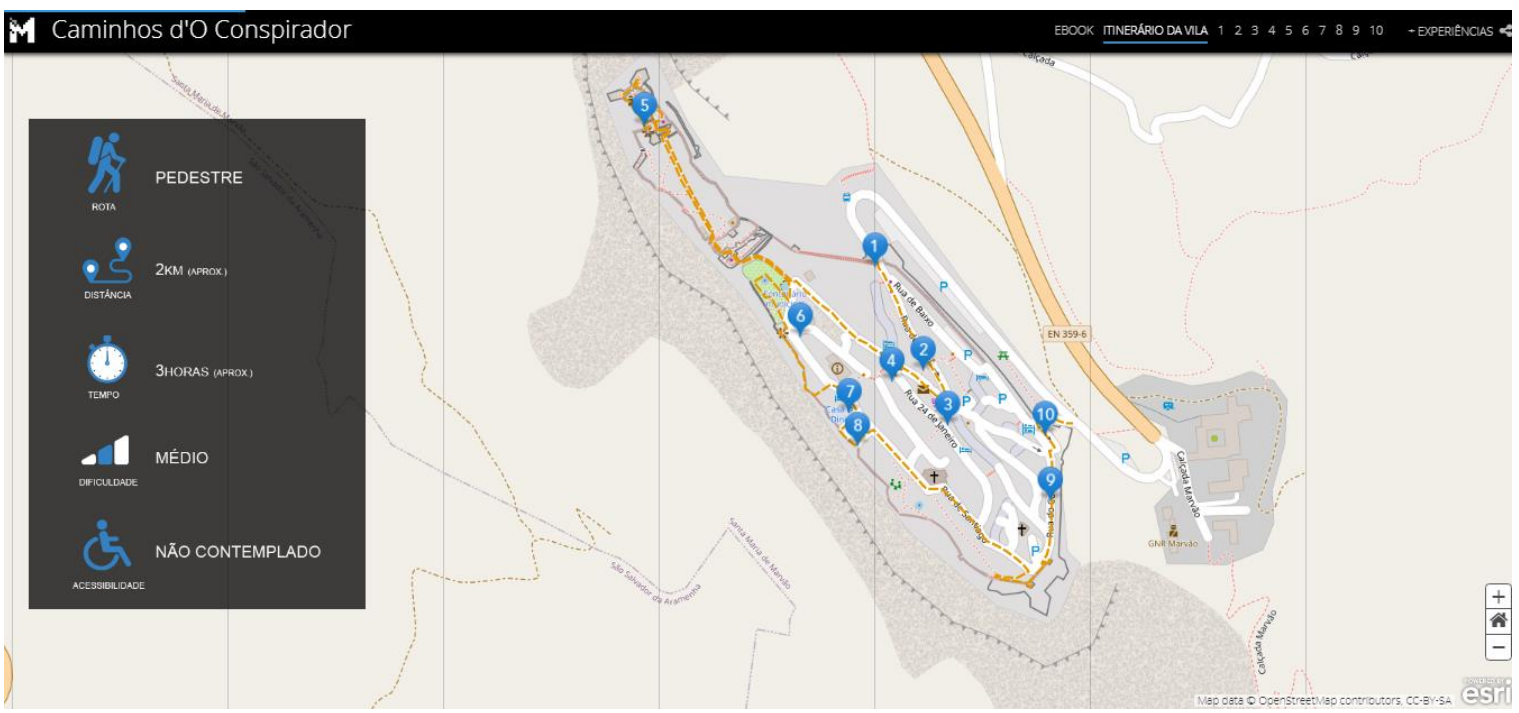

Neste mapa é possível clicar em cada um dos locais de interesse assinalados, de modo a abrir o respetivo pop-up onde consta a designação, uma pequena descrição e uma imagem com hiperligação ao catálogo do MUVITUR, acedendo-se deste modo a mais informação relativa a cada objeto digital.

Como indicado na figura 9, a informação sobre os locais de interesse, neste caso os antigos Paços do Concelho, surge em cascata à medida que se efetua scroll e os conteúdos dos pop-ups remetem para o património digital disponível no catálogo MUVITUR que permite a ilustração do itinerário que aqui se apresenta.

Figura 9. Screenshot do Story map com Pop-Up para os Antigos Paços do Concelho

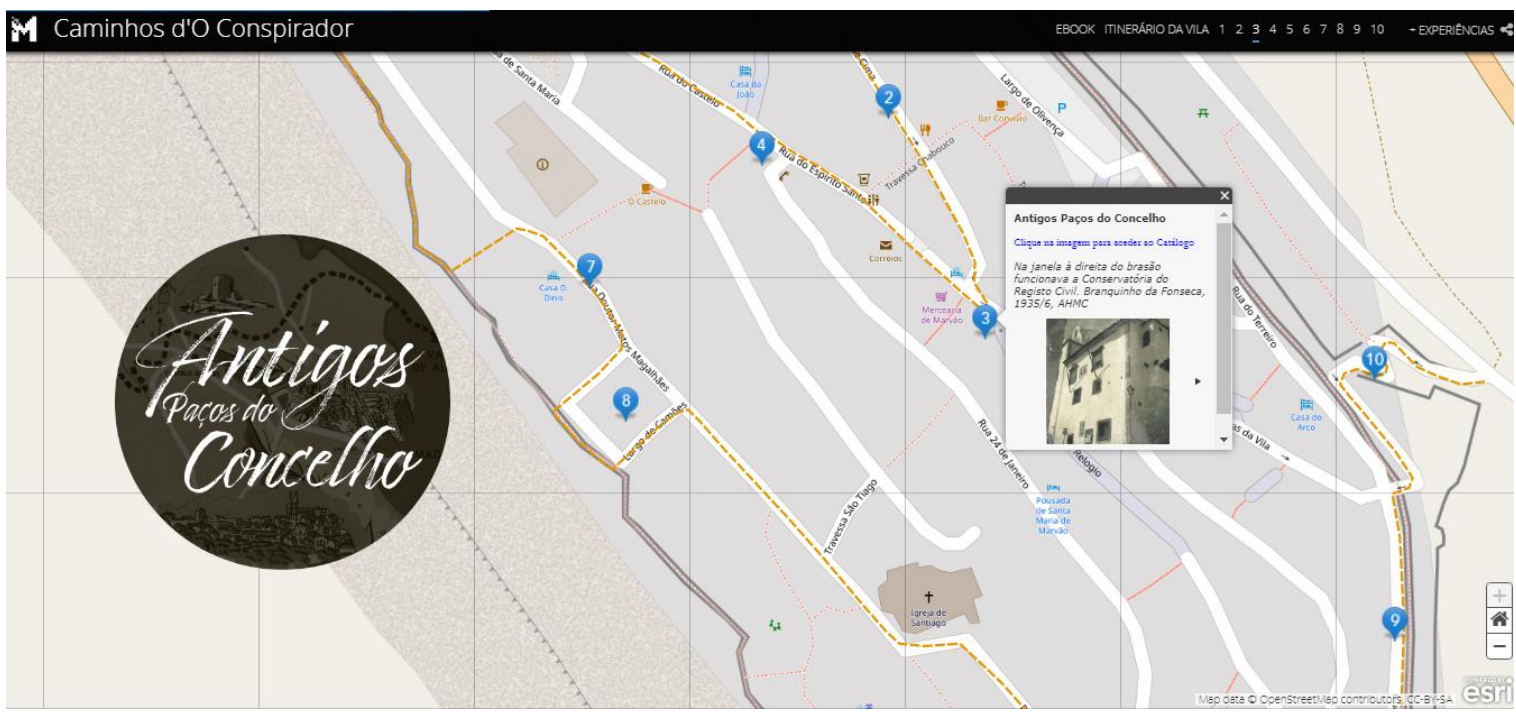

Ao percorrer o Story map é possível, entre outras valências, ler excertos do conto relacionados com os locais de interesse representados, com auxílio de desenhos e fotografias da autoria do próprio Branquinho da Fonseca, bem como fotografias recentes, algumas tiradas do mesmo ângulo de visão, o que permite compreender a evolução da paisagem urbana de Marvão. É o caso da figura 10, a qual permite ler um excerto do conto relativo à Igreja de Santa Maria, antiga 
Igreja Matriz e actual Museu Municipal de Marvão, mas igualmente comparar as imagens antigas e atuais deste património.

Figura 10. Screenshot do Story map com excerto do autor e imagens comparativas da Igreja de Santa Maria (atual Museu Municipal)

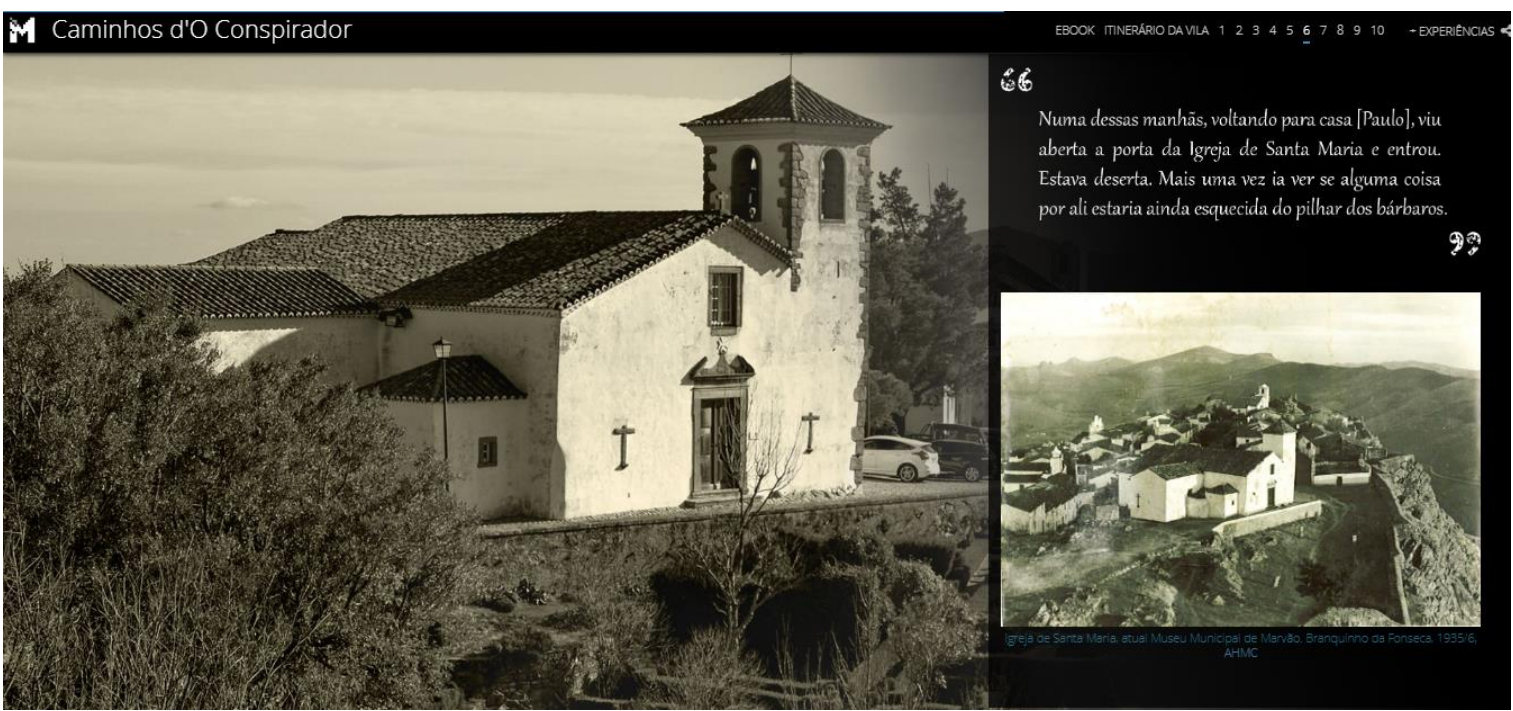

Ao explorar o Story map é possível encontrar excertos do conto e imagens comparativas da realidade atual com a que foi vivenciada por Branquinho da Fonseca. No caso da figura 11, tratase da Rua do Corro, no sentido descendente até às Portas da Vila, de onde se observa uma paisagem deslumbrante e uma coabitação entre a imponente rocha granítica e as habitações descritas por Branquinho da Fonseca: "Há casas verdadeiramente incrustadas no monte: à frente têm três andares e atrás o telhado toca no chão. É um labirinto de escadinhas toscas e vielas íngremes." (Almeida \& Oliveira, 2018: 17).

Figura 11. Screenshot do Story map com excerto do autor e imagens comparativas de Marvão

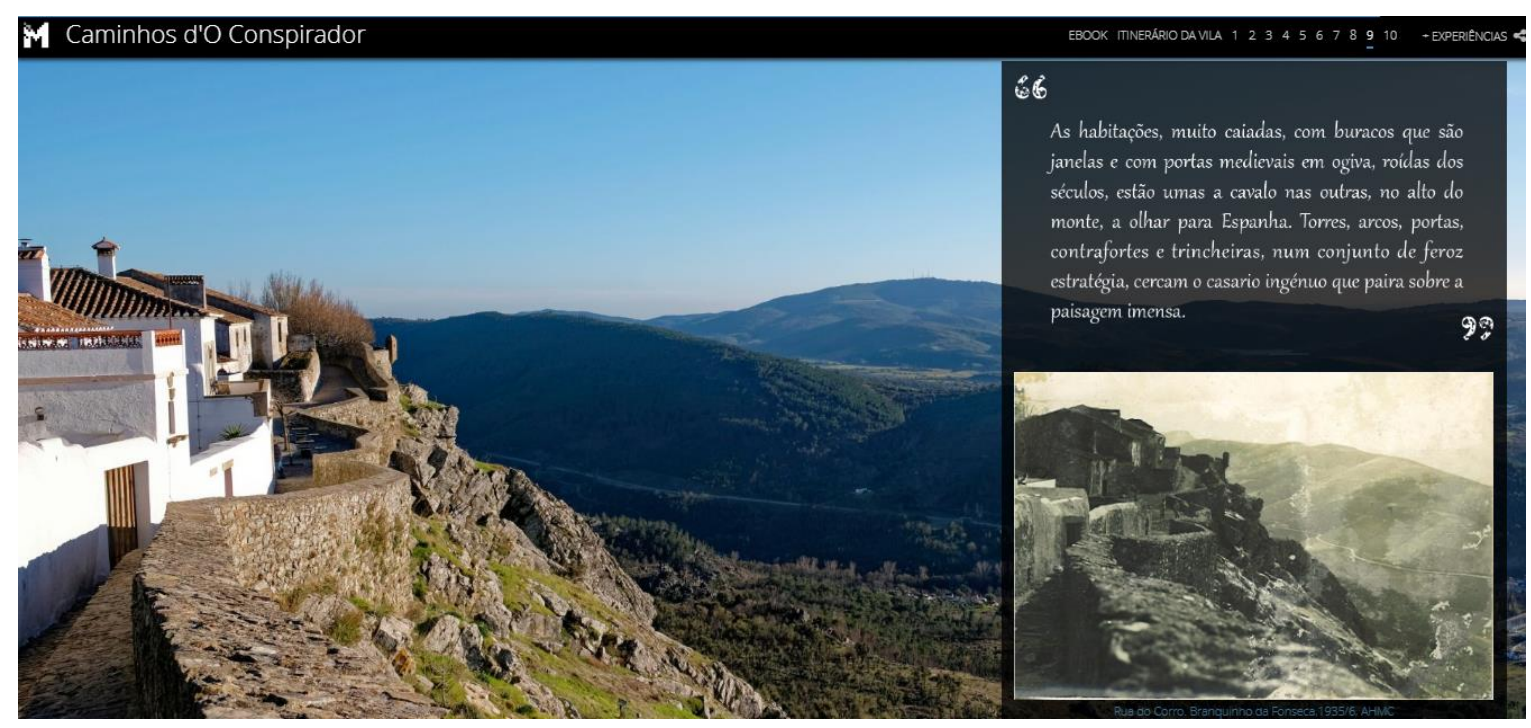


O output final do Story map Os Caminhos d'O Conspirador: itinerário da Vila de Marvão é disponibilizado no website do MUVITUR, mais concretamente na página dedicada às experiências proporcionadas pelo Museu Virtual do Turismo (Figura 12), cujo endereço URL é o seguinte: http://muvitur.eshte.pt/pt/experiencias.

Figura 12. Screenshot da página Experiências do MUVITUR

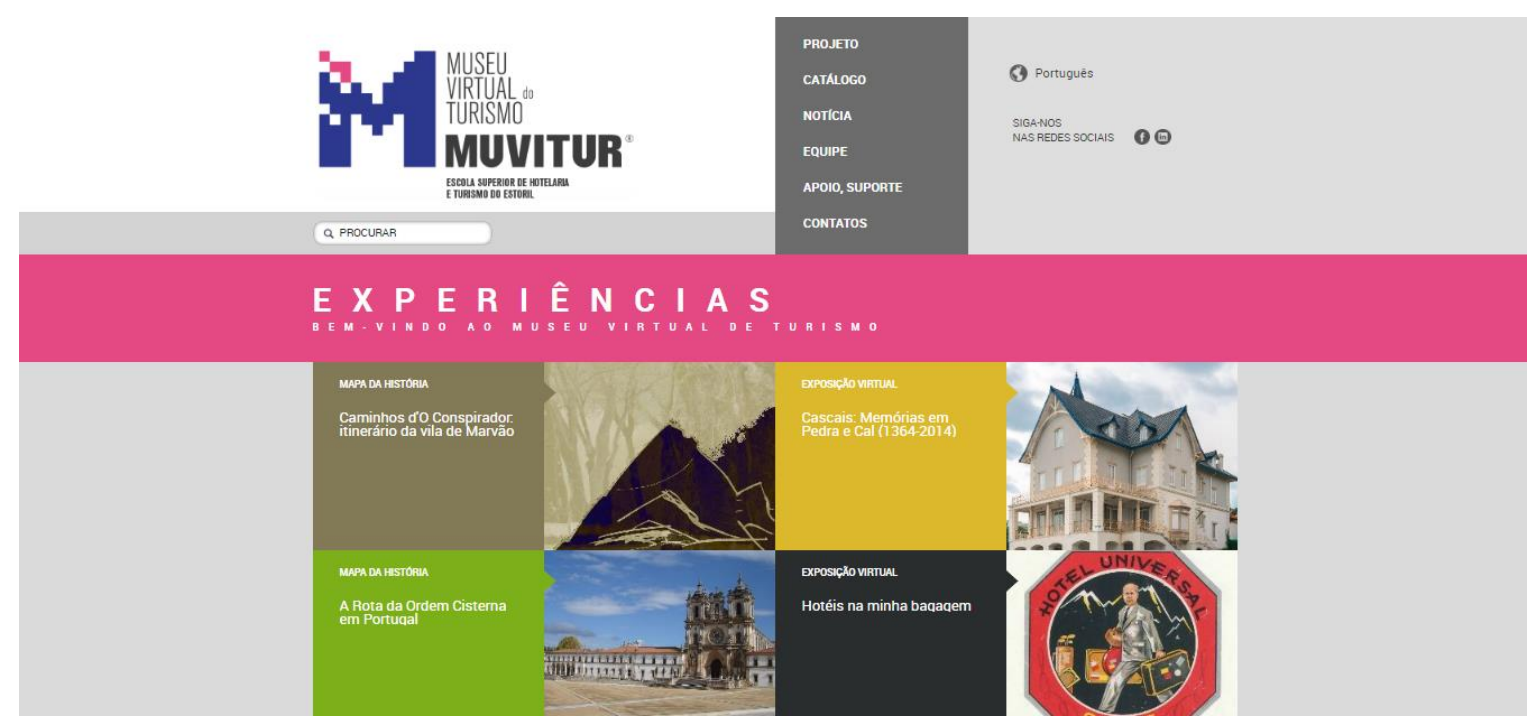

Fonte: Website do Muvitur.

Este projeto em que se articulou a literatura, o turismo e o storytelling apoiado pelas novas tecnologias de informação e comunicação, materializou muitas das considerações evidenciadas pelos autores na revisão da literatura. Permite, ao valorizar turisticamente as paisagens literárias, envolver emotivamente os utilizadores através das narrativas apresentadas de uma forma dinâmica e inovadora, podendo ter vários níveis de leitura, consoante os interesses individuais. Por outro lado, este tipo de abordagem transforma-se num elemento diferenciador na difusão cultural, promovendo um melhor conhecimento dos lugares ao desenvolver inovadoras estratégias de preservação patrimonial e territorial.

\section{Conclusão}

A produção e a divulgação do percurso literário foi possível graças à articulação de sinergias diversas sendo a base de dados do Museu Virtual do Turismo, a plataforma agregadora que possibilitou a escolha dos materiais que constituem a base do percurso. Parte das fotografias que o ilustram, da autoria do escritor Branquinho da Fonseca foram doadas ao Arquivo Histórico da Câmara Municipal de Cascais pelos seus herdeiros. Foram alvo de tratamento documental, digitalizadas e encontram-se disponíveis na página do Arquivo Histórico Digital em https://arquivodigital.cascais.pt/xarqweb/ que, por sua vez, é um dos fornecedores de conteúdos do MUVITUR. Também pudemos contar com a amabilidade da família Branquinho da Fonseca que nos cedeu dois desenhos feitos pelo escritor para ilustrar o conto "O Conspirador", que adaptámos, de modo a enriquecer visualmente o trabalho. O facto de o percurso já se encontrar estudado, traçado e publicado em ebook, facilitou bastante a sua transposição para o formato de apresentação utilizado.

Para tal, recorremos a tecnologia digital usando um aplicativo da Esri Portugal - Sistemas de informação geográfica, S.A., parceira do MUVITUR e distribuidora da tecnologia ArcGis que 
utilizámos para elaborar o story map "Caminhos d'O Conspirador: itinerário da vila de Marvão", uma combinação de funções interativas com texto narrativo, imagens e conteúdos multimédia, que permitem aproveitar o potencial dos mapas dinâmicos.

Tratando-se de uma aplicação com web design responsive, ou seja, que utiliza uma técnica que se adapta a todos os écrans e dispositivos, permite que qualquer visitante chegado à vila de Marvão possa, no seu smartphone ou tablet, fazer o percurso que propomos usufruindo da interatividade da experiência.

Considerando a gradual relevância que as paisagens literárias têm assumido na criação de territórios sustentáveis e na valorização das suas potencialidades endógenas, a promoção e divulgação deste story map poderá contribuir para incrementar as visitas à vila de Marvão, ajudando a fomentar a sustentabilidade deste território de baixa densidade.

O percurso literário de cariz local e urbano como o que ora propomos divulgado por meio de um story map, acessível e atrativo, poderá ser replicado noutros territórios, até de âmbito geográfico mais alargado, constituir um estímulo para o turismo literário em Portugal e para a divulgação da literatura portuguesa e dos escritores portugueses.

Paralelamente, este tipo de oferta de experiências culturais resultantes da reutilização de conteúdos e de curadoria digital, constitui uma mais valia para a divulgação do Museu Virtual do Turismo.

\section{Referências}

Aitken, S. \& Craine, J. (2006). Guest editorial: Affective geovisualizations. Directions Magazine.

Almeida, M. M. \& Oliveira, L. B. F. (2018). Os caminhos d'O Conspirador. Marvão: Câmara Municipal de Marvão.

Bouvet, R. (2019). La promenade littéraire, un dispositif pour des lecteurs en mouvement. Enjeux et société, 6(2), 109-140. doi: 10.7202/1066695ar

Brouillard, J., Loucopoulos, C. \& Dierickx, B. (2015). Digital storytelling and cultural heritage: Stakes and opportunities. AthenasPlus WP5, Creative Applications for the reuse of cultural resources.

Caquard, S. (2013). Cartography I: Mapping narrative cartography. Progress in Human Geography, 37(1), pp 135-144. doi: 10.1177/0309132511423796

Domingues, A. (2012). Vida no campo. Porto: Dafne Editora.

Henriques, E. B. (2010). Itinerários turísticos temáticos e património: Questões críticas para um turismo responsável e humanista. In M. da G. M. P. Santos (Org.), Turismo cultural, territórios e identidades (pp. 221-234) (Vol. III). Porto: Instituto Politécnico do Porto e Edições Afrontamento.

Herbert, D. T. (1996). Artistic and literary places in France as tourist attractions. Tourism Management, 17(2), 77-85. doi:10.1016/0261-5177(95)00110-7

Machado, A. (2012). Quinta do Amparo: Casa grande de Romarigães. Uma proposta de dinamização turística no Alto Minho (Projeto de defesa do Título de Especialista na Área do Turismo). Escola Superior de Hotelaria e Turismo do Estoril, Estoril.

Machado, A. (2020). Tormes, um lugar de criação da escrita: A paisagem literária enquanto estratégia de desenvolvimento sustentável. In Atas do XII Congresso da geografia portuguesa. Geografias de transição para a sustentabilidade (pp. 625-630) Guimarães: Universidade do Minho.

Machado, A. \& Moreira, F. J. de M. (2018). O turismo literário de Paredes de Coura como aposta de desenvolvimento local: Projeções e lugares de turismo cultural. In Atas do XVI Colóquio Ibérico de Geografia (pp. 685-692). Lisboa: Centro de Estudos Geográficos da Universidade de Lisboa. 
Martinho, F. J. B. (2007). Paisagem e Fuga: 'O Conspirador' de Caminhos Magnéticos. In A. M. Ferreira et al. (Eds.), Sobre Branquinho da Fonseca (pp. 7-26). Lisboa: Imprensa Nacional Casa da Moeda.

Moreira, F. J. de M. (2008). O turismo e os museus nas estratégias e nas práticas de desenvolvimento territorial (Tese de doutoramento não publicada). Universidade Lusófona de Humanidades e Tecnologias, Departamento de Arquitetura, Urbanismo e Artes, Lisboa.

Neves, M. S. (2011). A revista Presença e a consumação de um projeto de cosmopolitismo estéticoliterário. Limite, 5, 133-152.

Queiroz, Ana Isabel (2009). A paisagem das Terras do Demo. Lisboa: Esfera do Caos.

Quinteiro, S. \& Baleiro, R. (2017). Estudos em literatura e turismo: Conceitos fundamentais. Lisboa: Centro de Estudos Comparatistas da Faculdade de Letras da Universidade de Lisboa.

Sardo, A. (2009). Turismo literário: A importância do património e dos sítios literários para o desenvolvimento turístico regional. In J.M. Simões \& C.C. Ferreira (Eds.), Turismo de nichos: Motivações, produtos territórios (pp. 339-352). Lisboa: Centro de Estudos Geográficos, Universidade de Lisboa.

Varine, H. (2012). As raízes do futuro: O patrimônio a serviço do desenvolvimento local. Porto Alegre: Medianiz.

Aquilino MACHADo é professor assistente convidado no Instituto de Geografia e Ordenamento do Território, e Investigador do Grupo TERRITUR/Turismo, Património e Território do Centro de Estudos Geográficos, Universidade de Lisboa. Mestre e doutorando em Geografia Humana, encontra-se a concluir um projeto sobre as paisagens literárias urbanas em Aquilino Ribeiro e a geografia emocional que viveu e recriou nas cidades de Lisboa e Paris. Entre 2008 e 2013, deu aulas na Escola Superior de Hotelaria e Turismo do Estoril (ESHTE), onde obteve o título de Especialista na área de Turismo, realizando um trabalho sobre a importância do turismo literário no Alto Minho. Endereço institucional: Centro de Estudos Geográficos, IGOT, Universidade de Lisboa - Rua Branca Edmée Marques, Edifício IGOT, 1600-276 Lisboa, Portugal, aquilino.machado@campus.ul.pt

CONCEIÇÃo MACHADo é licenciada em História com especialização em Ciências Documentais e em Turismo. Coordenadora da Biblioteca da Escola Superior de Hotelaria e Turismo do Estoril. Coordenadora Técnica do MUVITUR. Endereço institucional: ESHTE - Av. Condes de Barcelona, n. ${ }^{\circ} 808,2769-510$ Estoril, Portugal, conceicao.machado@eshte.pt

FERnANDo JoÃo MoreIRA é licenciado em Geografia (FLUL), tem mestrado na área de Geografia Urbana e Planeamento Regional e Local (FLUL) e é doutorado na área de Turismo e Museologia (ULHT). Exerceu atividade profissional no ensino superior desde 1986. Foi Presidente da Escola Superior de Hotelaria e Turismo do Estoril entre 2009 e 2013, é membro do Conselho Técnico Científico desta escola. Mentor e Consultor Científico do MUVITUR - Museu Virtual de Turismo - ESHTE. Desenvolveu atividade profissional como consultor e conduziu um vasto número de estudos e projectos, para entidades públicas e privadas. Endereço institucional: ESHTE (área científica de planeamento turístico), - Av. Condes de Barcelona, n. ${ }^{\circ}$ 808, 2769-510 Estoril, Portugal, fernando.moreira@eshte.pt

JoÃo REIS é doutor em Geografia na área de especialização em Planeamento Regional e Urbano, no Instituto de Geografia e Ordenamento do Território da Universidade de Lisboa. Professor-Adjunto na Escola Superior de Hotelaria e Turismo do Estoril (ESHTE), diretor da licenciatura em Gestão Turística e membro da equipa técnica do Museu Virtual de Turismo (MUVITUR). Investigador no Centre for Tourism Research, Development and Innovation (CiTUR) na temática do Território e Destinos Turísticos. Tem participado em seminários e congressos no âmbito da geografia, do turismo e das tecnologias e colaborado com instituições de ensino superior, empresas e projetos como consultor e docente em planeamento, turismo, inovação e Sistemas de Informação Geográfica. Endereço institucional: ESHTE (área científica de planeamento turístico), Av. Condes de Barcelona, n. ${ }^{\circ} 808$, 2769-510 Estoril, Portugal, joao.reis@eshte.pt. 
MARIA JosÉ AURINDo é mestre em Antropologia (Especialidade Antropologia do Turismo na Faculdade de Ciências Sociais e Humanas da Universidade Nova de Lisboa), Pós-Graduada em Gestão Turística de Sítios (no Instituto de Novas Profissões), Licenciada em Geografia e Planeamento Regional (Variante Humana, na Faculdade de Letras da Universidade de Lisboa). Colabora atualmente com a Biblioteca Celestino Domingues da Escola Superior de Hotelaria e Turismo do Estoril (ESHTE). Coordenadora Operacional do MUVITUR. Colaboradora do Lit\&Tour - Cluster de Investigação em Literatura e Turismo - Centro de Estudos Comparatistas - FLULisboa. ESHTE - Av. Condes de Barcelona, n. ${ }^{\circ}$ 808, 2769-510 Estoril, Portugal, maria.aurindo@eshte.pt.

Maria Mota Almeida é doutora em Museologia. Equiparada a Professora Adjunta na Escola Superior de Hotelaria e Turismo do Estoril (ESHTE). Tem trabalhos publicados na área da museologia, património e turismo cultural e literário. É Investigadora Integrada no IHC, Universidade Nova. Coordena uma linha de investigação: Museums, Patrimony and Tourism | International Research Network - Local Museums and Tourism: innovations and contemporary challenges. Coordenadora Científica do MUVITUR - Museu Virtual de Turismo - ESHTE. Co - coordenadora do projeto - Ciclo da presença no Alto Alentejo. Colaboradora 'Atlas das Paisagens Literárias de Portugal Continental' IHC / IELT - Universidade Nova. Colaboradora do Lit\&Tour - Cluster de Investigação em Literatura e Turismo - Centro de Estudos Comparatistas - FLULisboa. Endereço institucional: Departamento de Ciências Sociais e Humanas, ESHTE, 2765-273, Estoril, Portugal, maria.almeida@eshte.pt

Rita TABorda Faria é licenciada em Design (IADE), colabora atualmente na Biblioteca Celestino Domingues da Escola Superior de Hotelaria e Turismo do Estoril (ESHTE). Tem a responsabilidade do Design do MUVITUR. Endereço institucional: ESHTE - Av. Condes de Barcelona, n. ${ }^{\circ}$ 808, 2769-510 Estoril, Portugal, rita.faria@eshte.pt 